Journal of Social Sciences 6 (3): 483-487, 2010

ISSN 1549-3652

(C) 2010 Science Publications

\title{
A Study of Forms and Linguistic Usage of Meeting Documents in the Reign of His Majesty King Chulalongkorn and the Reign of His Majesty King Bhumibol Adulyadej
}

\author{
Preeya Hiranpradit \\ School of Liberal Arts, Sukhothai Thammathirat Open University Jaengwattana Road, \\ Pakred, Nonthaburi 11120, Thailand
}

\begin{abstract}
Problem statement: At present, meeting is an activity which is necessary for work. Gathering for discussing or solving problems is assumed that it has been held since the reign of His Majesty King Chulalongkorn. The purposes of this research were these: (1) to investigate forms of meeting documents in the reign of His Majesty King Chulalongkorn and the reign of His Majesty King Bhumibol Adulyadej, (2) to analyses meeting procedures from the minutes of the meetings in the reign of His Majesty King Chulalongkorn and the reign of His Majesty King Bhumibol Adulyadej and (3) to analyses Thai usage in the minutes of the meetings in the reign of His Majesty King Chulalongkorn and the reign of His Majesty King Bhumibol Adulyadej. Approach: The meeting documents in the reign of His Majesty King Chalalongkorn such as microfilms and four books of script photos were analyzed, they consisted of four meeting document: (1) the minutes of the meeting of the Minister Council in the first session on the Council of State Affairs Councilor, (2) the minute of the meeting of the Minister Council in Rattanakosin Era of 111, (3) the minute of the meeting of the Minister Council in the second session, part one in Rattanakosin Era of 112 and (4) the minutes of the meeting of the Minister Council in the third session in Rattanakosin Era of 113. A total pages of these documents was 1,000 pages. A sample was 6 experts I creating meeting documents and 1 linguistic expert. Research data were collected by means of an interview, the data were analyzed by means of an interpretation and a composition technique and were presented by means of a descriptive analysis. Results: (1) Forms of meeting documents in the reign of His Majesty King Chulalongkorn and His Majesty King Bhumibol Adulyadej consisted of these: (i) A law of meeting regulations, (ii) a document of meeting schedule and agenda, (iii) the minutes of the meeting, (iv) a meeting document and (v) an after-meeting document (2) Meeting procedures in the reign of His Majesty King Chulalongkorn were proceeded according to a law of meeting regulations; for example the regulations of the meeting, the minutes of the meeting and the Royal Decree on Principle ad procedure for discussion meeting. Meeting procedures in the reign of His Majesty King Bhumibol Adulyadej divided into 2 types were these: (i) holding a meeting according to regulations ad holding a meeting according to an agenda (general meeting) (ii) Thai usage in the minute of the meeting in the reign of His Majesty King Chulalongkorn ad His Majesty King Bhumibol Adulyadej had the differences in writing style, idioms, outlines and technical terms. Conclusion/Recommendations: Research results revealed the difference in forms and linguistic usage of meeting documents between in the reign of His Majesty King Chulalongkorn ad His Majesty King Bhumibol Adulyadej, especially the differences in writing styles, idioms, outlines and technical terms concerning the meeting.
\end{abstract}

Key words: Linguistic usage, King Chulalongkorn, Rattanakosin Era, Bhumibol Adulyadej, meeting documents

\section{INTRODUCTION}

Meeting is the coming together or the calling out of people for some purpose like the meeting of the committee. At present, meeting is an important activity for a international level, a national level and an organizational level. Some examples of the purpose of the meeting are for solving problems, for discussing and sharing knowledge, for discussing and searching practical guideline, for creating a positive attitude and for declaring policies or information so the meeting is an activity which gives a chance for many people to involve. The meeting has played an important role since the reign of His Majesty King Chulalongkorn; he held 
the meeting in the court, established the Council of State Affairs Councilor and established the Privy Council and other Councils. Meeting documents resulted from those meetings were a meeting agenda, the minute of the meeting, the meeting regulations and moreover His Majesty King Chulalongkorn enacted the Royal Decree on Principle and procedure for discussion of the Minister Council, the Privy Council and the Minister of State Council (The Royal Institute, 1999)

The meeting has been held until the reign of His Majesty King Bhumibol Adulyadej which Thailand is ruled by democracy and the king of the head of the kingdom. Each meeting need meeting documents in order to facilitate the meeting to reach a success in purpose and to use as evidence or reference things; for example a letter of meeting invitation, a document of meeting agenda, a meeting document ad the minutes of the meeting. In case of an important meeting, it must need a document of principle and procedure for a meeting.

As mentioned above, these meeting documents are useful for a study of Thai political history in the reign of His Majesty King Chulalongkorn and useful for a study of the development of meeting documents from the past to the present. Purposes and objects: (1) to investigate forms of meeting documents in the reign of His Majesty King Chulalongkorn and the reign of His Majesty King Bhumibol Adulyadej, (2) to analyzes meeting procedure from the minutes of the meetings in the reign of His Majesty King Chulalongkorn and the reign of His Majesty King Bhumibol Adulyadej and (3) to analyses Thai usage in the minutes of the meetings in the reign of His Majesty King Chulalongkorn ad the reign of His Majesty King Bhumibol Adulyadej.

\section{MATERIALS AND METHODS}

Population ad sample: Six experts in creating meeting documents and 1 linguistic expert.

Instruments: Research instruments were an interview form and a sound recorder.

Data analysis: The data were analyzed by means of a interpretation and a composition technique and were presented by means of a descriptive analysis.

\section{RESULTS}

\section{Research results were as follows:}

Forms of meeting documents: Forms of meeting documents in the reign of His Majesty King Chulalongkorn and the reign of His Majesty King Bhumibol Adulyadej into 5 types:
- The laws of meeting regulations, they divided into 2 types were these: (1) an Act and (2) a Royal Decree. 5 laws of meeting regulations consisted of the following; the first was an Act of Council of State and an Act of Privy Councilor, both Acts were enacted in the same time and were gathered together; the second was a Royal Decree on Principle and Procedure for Discussion of Council of Ministers, Council Privy and Council State (1892 AD); the third was a Royal Decree on Privy Councilor and the fifth was a Royal Decree on Ministers of State or Juries of the Royal Court, this law had 99 statutes and in the reign of His Majesty King Bhumibol Adulyadej had only one form, it was classified as a commanding document which supported by the regulation of the Office of the Prime Minister on Document Recording of the year 1983

- A document of the date and agenda of the meeting; it was formed into a letter in the reign of His Majesty King Chulalongkorn, the agenda for the meeting divided into 5 groups: (1) the urgent agenda, (2) the budget of Ministries, (3) the justice system, (4) the affairs of Ministries and (5) the confirmation of the minutes of the last meeting, the writing style of the title of agenda was written into a phrase or a sentence. In the reign of His Majesty King Bhumibol Adulyadej; a document of the date and agenda for the meeting strictly respected the regulation of the Office of the Prime Minister on Document Recording of the year 1983, it was formed into an external document in case of it was sent to the different state affiliation but it was formed into an internal document in case of it was sent to the same state affiliation. The agenda for the meeting was set as follows: (1) President's report, (2) Review and approval of the minutes of the last meeting, (3) Matters for presenting, (4) Matters for considering and (5) Any other matters. A document of the date and agenda for the meeting was formed into 2 types: (1) a document which was attached to the agenda ad (2) a document which the agenda was written down in it

- The minutes of the meeting; the minutes of the meeting in the reign of His Majesty King Chulalongkorn divided into 3 types: (1) a meeting record, (2) the minutes of the sequences of discussion and (3) the minutes of the meeting agenda. The minutes of the meeting in the reign of His Majesty King Bhumibol Adulyadej divided into 2 types: (1) the minutes of the meeting which recorded all of the words and (2) the minutes of the meeting which recorded essential content 


\section{J. Social Sci., 6 (3): 483-487, 2010}

- A meeting document; a meeting document in the reign of His Majesty King Chulalongkorn divided into 2 types: (1) a private letter and (2) a state letter with the number of reference. In the reign of His Majesty King Bhumibol Adulyadej, it was formed into a state document which respected the regulation of the Office of the Prime Minister on Document Recording of the year 1983, it could varied to an external or internal document, a commanding document, a reporting document or any other document which use as the information or evidence for the meeting

- An after-meeting document, an after-meeting document in the reign of His Majesty King Chulalongkorn was formed into a letter for reporting an agreement of the committee. In the reign of His Majesty King Bhumibol, it divided into 2 types: (1) an external or an internal document for reporting or assigning the person involved to know or to practice according to an agreement of the committee and (2) a document of the conclusion of an agreement of the committee for reporting the person involve

Meeting procedures: In the reign of His Majesty King Chulalongkorn, all the meeting committee proceeded their meetings according to the laws. During this period the regulation of the meeting, the record of the meeting and the Royal Decree on Principle and Procedure and Procedure for Discussion Meeting were enacted.

Meeting procedures in the reign of His Majesty King Bhumibol Adulyadej divided into 2 types: (1) a meeting procedure according to meeting regulations and (2) a meeting procedure according to a meeting agenda.

Linguistic usage I meeting documents: Thai linguistic usage in meeting documents in the reign of His Majesty King Chulalongkorn had the outstanding points as follows: (1) Thai linguistic usage in the letters of His Majesty King Chulalongkorn revealed that he used his royal prerogative with the ten virtues of the king and tried to educate courtiers and people about democratic knowledge by using a writing style according to the principles of international letter writing which has a communicative efficiency were these: (i) clear, (ii) concise, (iii) correct, (iv) courteous, (v) conversational, (vi) convincing and (vii) complete (2) Thai linguistic usage in meeting documents in the reign of His Majesty King Chulalongkorn and the reign of His Majesty King Bhumibol Adulyadej focused on 7 points were these: (i) the purposes of linguistic usage, (ii) a title of topic or agenda, (iii) a outline of the content of meeting agenda and the minutes, (iv) the elements of the minutes, (v) linguistic usage in other meeting documents, (vi) linguistic usage in the laws concerning the meeting and (vii) technical terms concerning the meeting in the reign of His Majesty King Chulalongkorn.

Writing styles and idioms in meeting documents in the reign of His Majesty King Chulalongkorn revealed that they had the outstanding point as follows: (1) using ancient idioms which no using at present, (2) using idioms which have been using at present and their meanings are the same as in the past or different a little bit, (3) using a poetic-Thai writing style which written in rhyme, (4) using a final voiced consonant which is difference from the present use, (5) using foreigntechnical terms together with Thai words, (6) using a formal title which is difference from the present use, (7) using classifiers more than they are used at present and (8) using popular words in that period for example Siam, Thai and Bangkok.

\section{DISCUSSION}

Forms of meeting documents: Forms of meeting documents in the reign of His Majesty King Chulalongkorn and the reign of His Majesty King Bhumibol divided into 5 forms were these: (1) the laws and regulations concerning the meeting, (2) a document of the date and agenda of the meeting, (3) the minutes of the meeting, (4) a meeting document and (5) an after-meeting document. Forms of meeting documents in the reign of His Majesty King Chulalongkorn were adapted from the forms of western-meeting documents and they were developed to the prototypes of meeting documents in the latter period and the present. A document of the date and agenda of the meeting, a meeting document and a document of an agreement of the meeting in the form of a letter in that period is a prototype of an external document and an external document of state organizations. The minute of the meeting in the present which are developed from meeting records in the reign of His Majesty King Chulalongkorn are some examples which represent the development of meeting documents, this is consistent with the Office of the Prime Minister (1983) enacted the Regulation on Document Recording of the Year 1983, this regulation classified the minutes of the meeting as the evidence or the documents which each state organization made them for referring.

Meeting procedure: All of the meeting committee preceded their meetings according to the laws. In the reign of His Majesty King Chulalongkorn and His Majesty King Bhumibol Adulyadej, the regulation of 
the meeting, the record of the meeting and the Royal Decree on Principle and Procedure for Discussion Meeting were enacted. Meeting procedures divided into 2 types: (1) a meeting procedure according to meeting regulations, for example the Assembly the Assembly of the People's Representatives signals the beginning of the meeting when it has a quorum ad (2) a meeting procedure according to a meeting agenda; this meeting procedure begins from raising meeting issues which should not over 10 issues, reporting the matters by the president, confirming the minutes of the meeting to reporting an agreement of the committee, this is consistent with Secretariat of the Prime Minister (2002), he says that "when will be held the meeting; the clerk of Council sent letters of meeting invitation to the persons involved at least $24 \mathrm{~h}$ before the meeting begins except in case of a state of emergency, those involved must urgently come to meeting and a quorum should at least consists of 7 in 20 people, when the meeting begins the clerk reads the minutes of the last meeting to the committee, if no any opposition the vice-president signs a confirmation document in case of some committee have any opposition, the committee must approve the minutes again.

Thai usage in meeting documents: Thai usage in meeting documents revealed 7 outstanding points as follows:

- The purposes of Thai usage in meeting documents in the reign of His Majesty King Chulalongkorn and the reign of His Majesty King Bhumibol Adulyadej were these: (1) to persuade people involved to take action and (2) to inform people involved of important information

- Writing Style in the title or agenda of the meeting in the reign of His Majesty King Chulalongkorn and the reign of His Majesty King Bhumibol revealed that it was rather written as a noun more than a verb but the title ad agenda in the reign of His Majesty King Chulalongkorn was shorter than it is at the present

- Writing style in the outline of agenda and the minutes of the meeting in the reign of His Majesty King Chulalongkorn revealed that it consisted of 3 parts: (1) the title of agenda, (2) the discussion of the committee and (3) the agreement of the committee, a descriptive writing was used in all parts, a concise feature, a clear feature and a meaningful feature were the features of Thaiwriting style in those documents. Writing style in the same document in the reign of His Majesty King Bhumibol Adulyadej had the features in terms of a concise feature, a clear feature, a meaningful feature and a formal writing style feature

- Writing style in the content of the minute of the meeting in the reign of His Majesty King Chulalongkorn revealed that the upper part of the minutes was written down the date of the meeting both in Thai and English styles and also written down the names of the real attendances and arrival time. Writing style in the content of the same document in the reign of His Majesty King Bhumibol Adulyadej respect the regulation of the Office of the Prime Minister on Document Recording which was different from in the reign of His Majesty King Chulalongkorn in term of the upper part of it was written down the date of the meeting in English style and also written down the names of both the present and the absent attendances and in the lower part of the minutes of the meeting was written down only the terminal time and the name of a recorder

- Writing style in any other meeting documents in the reign of His Majesty King Chulalongkorn like a document of meeting invitation and a meeting document revealed that it was formed into a letter which used an opening word and an ending word in accordance with the status of the receiver. It always began with a word which represented reasons or purpose of writing a letter by using a free writing style of the writer. Writing style in the same document in the reign of His Majesty King Bhumibol Adulyadej respected the regulation of the Office of the Prime Minister on Document Recording of the Year 1983, an opening word was "To" and an ending word was "Sincerely yours," and began the first sentence with the reason or the purpose of writing a letter but if the sender and receiver has continuously sent the letter to each other, the opening sentence always began with a word of "According to..." and followed with the word which represented the reason or purpose of writing a letter in a formal writing style

- Writing style I 5 laws concerning the meeting in the reign of His Majesty King Chulalongkron had the features in terms of a clear feature, a concise feature and a systematic unity feature. A discussion ad a classification writing style were used and moreover a poetic writing style was also used in these laws. Writing style in 2 laws concerning the meeting in the reign of His Majesty King Bhumibol Adulyadej had the same features like in the reign of His Majesty King Chulalongkorn but it focused on persuading people involved to take action 
- Technical terms concerning the meeting in the reign of His Majesty King Chulalongkorn has been used from the past to the present but some word was a little bit adapted in its meaning, some examples of these words were meeting agenda, a quorum, the minutes of the meeting, a meeting, meeting place, the president of the meeting, an agreement of the meeting, voting, arrival time, terminal time

As mentioned above, Thai usage in meeting documents in the reign of His Majesty King Chulalongkorn ad the reign of His Majesty King Bhumibol Adulyadej is consistent with the research result of Kannika et al. (2010). The Integration of Proverbs from Thai Didactic Literary Works for Secondary Students. The research findings were presented information of descriptive analysis. For histories of the uses of proverbs in Thai didactic literary works, theproverbs aimed to teach people involving honesty, discipline; love of the country, religion and the king; grateful to people to whom you are obligated and attention to learning. The proverbs teach us to live sufficiently, to intend to study, to love Thainess and to have public awareness. The proverbs teach us to have good behaviors, to talk politely, to speak straightforward the purpose needed, to teach about beliefs, merits, deeds, black magic and magic, to teach about association with other people, to keep cool, not to be frightened easily and not to believe rumor and bad news. The proverbs teach about forgiveness perseverance, cultures, traditions which are good to everyone in the society so that they will live happily together to have love and unity. For the current conditions of the uses of Thai didactic literary works, they are used for teaching at schools only. After graduation from their schools, these people seldom study further to increase knowledge of proverbs. The teachings will be in the form of modern literary works by writing novels, short stories and writing verses. For the integration of proverbs from Thai didactic literary works for secondary school students, from the conditions of problems of students' learning the following are found. Not a small number of students are absent from class, cannot catch up with peers' learning, submit assignments late and do not pay attention to learning. They have problems of aggressive behaviors, improper sexual behaviors, drugs, game addiction, quarrels, extravagance, to mistake wrong for right, preference for using violence to judge problems and admire rich people although they are dishonest, preference for disruption, are fond of western culture and not love Thainess.

\section{CONCLUSION}

Research results revealed forms and linguistic usage of meeting documents in the reign of His Majesty King Chulalongkorn and the reign of His Majesty King Bhumibol Adulyadej and pointed out the differences in forms and linguistic usage of meeting documents between the both reigns. The persons involved can apply these results to develop meeting documents of their organizations.

\section{ACKNOWLEDGEMENT}

The researcher would like to express my sincere thanks to all persons involved who supported this research.

\section{REFERENCES}

Kannika, S., B. Yodmalee and S. Potisan, 2010. The integration of proverbs from Thai didactic literary works for secondary students. J. Soc. Sci., 6: 404-407. DOI: $10.3844 / .2010 .404 .407$

Secretariat of the Prime Minister, 2002. A Report of the meeting of the Minister Council in the Reign of His Majesty King Chulalongkorn is the First Session on the Council of State Affairs Councilor. 1st Edn., The Committee of Thai Historical Revision, Bangkok, ISBN: 9749545133, pp: 144.

The Office of the Prime Minister, 1983. The regulation of the office of the prime minister on document recording of the year 1983. The Office of the Prime Minister, http://www.kromchol.com/eoffice/law.htm

The Royal Institute, 1999. Thai Dictionary of the Royal Institute of the Year 1999. 1st Edn., Nanmee Books, Bangkok, ISBN: 974-9588-04-5, pp: 1436. 